\title{
Regional left ventricle wall function in acute myocarditis as assessed by 2-dimensional speckle tracking echocardiography
}

\section{Andreja Černe Čerček* \\ Pavel Berden \\ University Medical Centre,} Ljubljana, Slovenia
RECEIVED:

March 31, 2015

ACCEPTED:

April 20, 2015
KEYWORDS: myocarditis, strain echocardiography, magnetic resonance imaging. CITATION: Cardiol Croat. 2015;10(3-4):58. | DOI: http://dx.doi.org/10.15836/ccar.2015.58 ORCID: Andreja Černe Čerček, http://orcid.org/0000-0001-7680-0643

*ADDRESS FOR CORRESPONDENCE: Andreja Černe Čerček, KO za kardiologijo, Univerzitetni klinični center Ljubljana, Zaloška 7, 1000 Ljubljana, Slovenija. Phone: +38640626394. E-mail: andreja.cerne@kclj.si

|l||||||||||||||||||||||||||||||||||||||||||||||||||||||||||||||||||||||||||||||||||||||||||||||||||||||||||||||||||||||||||||||

BACKGROUND: Left ventricle (LV) contractile function depends on a complex longitudinal, circumferential and radial deformation. LV ejection fraction (LVEF) is not an ideal measure of subtle decrease in regional LV function in acute myocarditis due to selective damage of the subepicardial layers. Speckle tracking echocardiography is a more accurate technique for quantifying myocardial deformation and might denotes subtle longitudinal dysfunction in these patients.

AIM: The aim of our study was to assess longitudinal and circumferential strain of the LV in patients with acute myocarditis and to correlate these findings with the cardiac magnetic resonance imaging (CMR) results.

METHODS: Thirty consecutive patients (age $30 \pm 8,90 \%$ male) with acute myocarditis mimicking acute coronary syndrome and preserved LVEF were compared to 30 age and sex-matched healthy participants. All the patients had elevated troponin I (11.5 $\pm 8.3 \mathrm{ng} / \mathrm{L})$, normal coronary angiogram and CMR evidence of late gadolinium enhancement (LGE). Global longitudinal (GLS) and circumferential (GCS) strain was assessed by 2-dimensional speckle tracking echocardiography in all participants.

RESULTS: Multiple areas of subendocardial LGE were detected in all patients, additional intramural LGE lesions were found in three $(10 \%)$ patients. GLS was significantly decreased in the myocarditis group as compared to controls ( $-15 \pm 2 \%$ vs. $-20 \pm 4 \%$, $p<0.01$ ), while no significant difference in GCS was observed between the two groups. However, a reduced GCS was detected in patients with intramural LGE (patient No.8, No.13 and No.17: - $16 \%,-14 \%$ and $-10 \%$ ). In the myocarditis group, segments with LGE showed significantly lower GLS in comparison to segments without LGE $(-15 \pm 6 \%$ vs. $-18 \pm 6 \%, p<0.01)$. A GLS cut-off point of <- $16 \%$ was able to identify $92 \%$ of the lesions with LGE.

CONCLUSIONS: In patients with acute myocarditis and preserved LVEF, longitudinal deformation is diffusely impaired and being lowest in the areas with CMR detected subepicardial damage.

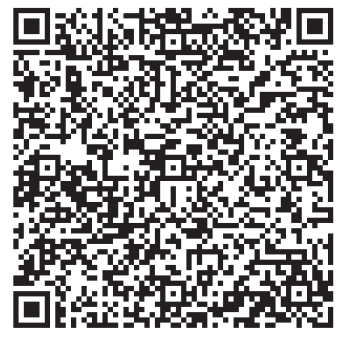

